\title{
Water Stress Implications of Energy Scenarios for the Middle East: An Assessment of Risks and Uncertainties
}

\author{
Bob van der Zwaan, Matthew Halstead, and Tom Kober
}

\begin{abstract}
Energy, water, and food systems have so far mostly been studied independently. In this chapter, we argue that it is important to take an "energy-water-food nexus approach" to analyzing these three resource systems. After briefly introducing the emerging literature on the energy-water-food nexus, we inspect the interrelationship between energy and water use in the Middle East. We present results for projected power production, water withdrawal, and water consumption levels until 2050 in the Middle East under both baseline and stringent climate policy scenarios. We also analyze how the use of different cooling techniques for the main power production options in the Middle East can yield water withdrawal and consumption savings in the electricity sector in the region. We end by informing authorities responsible for the implementation of energy-water policies on the risks and uncertainties associated with the water usage of future energy systems.
\end{abstract}

Keywords Energy-water-food nexus - Climate change - Energy scenarios · Risks · Uncertainties · Middle East

\footnotetext{
B. van der Zwaan ( $₫)$

Energy Research Centre of the Netherlands (ECN), Policy Studies, Amsterdam, The Netherlands

Johns Hopkins University, School of Advanced International Studies (SAIS), Bologna, Italy

University of Amsterdam, Faculty of Science (HIMS), Amsterdam, The Netherlands

e-mail: vanderzwaan@ecn.nl

M. Halstead

Energy Research Centre of the Netherlands (ECN), Policy Studies, Amsterdam,

The Netherlands

T. Kober

Laboratory for Energy Systems Analysis, Paul Scherrer Institute (PSI), Villigen, Switzerland
}

(C) The Author(s) 2019

H. Doukas et al. (eds.), Understanding Risks and Uncertainties in Energy and

Climate Policy, https://doi.org/10.1007/978-3-030-03152-7_6 


\section{Introduction}

In this chapter, we inspect possible water stress implications of energy scenarios developed by an integrated assessment model (IAM). We analyze the potential impacts of developments in the energy sector on requirements from the water sector in a case study for the Middle East, since it is a region in which water stress is likely to become more and sooner apparent than in other parts of the world. We perform our analysis through an assessment of risks and uncertainties. In this chapter, we start by pointing out that energy scenarios are subject to sizeable uncertainties, because they are determined by the parameter values used in, or simulation constraints applied to, the models that generate them. A substantial degree of freedom exists with regard to the choice of parameter values as well as simulation constraints. As a matter of fact, because of these uncertainties, the IAM literature employs the terminology of "scenarios" or "projections," rather than "forecasts" or "predictions."

Below, we show that energy scenarios may involve risks in terms of water usage versus availability and that large disparities exist regarding water use risks between different scenarios. We demonstrate that these risks can be mitigated through technological change and that the water use uncertainties of energy scenarios can be reduced. We quantify these uncertainties and calculate the levels to which the risks can be lowered by developing a set of scenarios for energy and water use in the Middle East with the TIAM-ECN model. TIAM-ECN is an established IAM that has been used for a variety of energy and climate policy analyses over the past decade. Last but not least, we make recommendations for policy-makers, explain that they should be well aware of the possible risks and uncertainties involved in energy and water usage scenarios, and point out the directions in which these risks and uncertainties can be addressed. For the energy and water modeling communities, we make suggestions for how their research can be improved, not only by integrating their respective fields of work but also by explicitly accounting for the risks and uncertainties associated with the scenarios they develop.

The first section of this chapter begins by introducing the published literature on the energy-water-food nexus-often referred to as "the nexus"-in the context of which our work has been performed. The nexus is a broad and still largely undefined and poorly understood concept and constitutes a field of research in statu nascendi. In the following section, we thus narrow down our focus to predominantly inspect the interrelationship between energy and water as applied to the Middle East. In the last two sections, we present and discuss the results of our analysis and formulate a list of conclusions and recommendations, respectively. With our chapter, we intend to inform authorities responsible for the development and implementation of energywater policies on the risks associated with the water use of future energy systems, notably in the context of efforts to mitigate global climate change. We perform an uncertainty analysis by inspecting various scenarios for future energy demand and deployment of low-carbon energy technologies in the Middle East. 


\section{The Energy-Water-Food Nexus}

Energy, water, and food resource systems are fundamentally interrelated. We need energy to produce food and to treat and move water; we need water to cultivate food crops and to generate essentially any form of energy; and we need food to support the world's growing population that both generates and relies on energy and water services (Halstead et al. 2014). Land availability also constitutes an important element in each of these three resources with important economic consequences, for example, for crop production, for either food or energy purposes (OECD 2017). This mutual relationship is defined as the "energy-water-food nexus." To date, the three individual resource systems of energy, water, and food have mostly been organized and studied independently. In a rapidly developing world with ever more pressing environmental challenges, however, choices and actions in each of these three domains can significantly affect the others, positively or negatively. Therefore, it is important to take a "nexus approach" to analyzing these three resource systems. Conventional policy- and decision-making with regard to each of these domains in isolation is not necessarily anymore the most effective or optimal course of planning or action. A nexus approach-which in our context refers to the multidisciplinary analysis of the relationship between energy, water, and food-can help to reduce trade-offs and to build synergies across these different sectors. In an increasingly complex and interrelated world, this approach can lead to better and more efficient resource use as well as cross-sector policy coherence.

Water scarcity already affects every continent. Around 1.2 billion people, almost one fifth of the world's population, live in areas of scarcity. Another 1.6 billion people, almost one quarter of the global population, face economic water shortage, which means that countries lack the necessary infrastructure to take water from rivers and aquifers. It is estimated that by 2030 almost $50 \%$ of people on the planet will be living in areas of high water stress with a likely impact on energy and food security (UN 2014). Even though water is a renewable resource, and sufficient water is available globally to satisfy an expanding and wealthier population, demand for water already exceeds supply in many regions of the world. At present, this supplydemand imbalance is most commonly seen in, for instance, Brazil, China, India, and South Africa, as well as in countries in the Middle East and North Africa (referred to as the MENA region; see SEI 2011).

For pursuing analyses involving water-related issues, one needs to distinguish between three different types of water use: water withdrawal, water consumption, and water discharge. Water withdrawal is the total amount of water taken from a source (groundwater or surface water). Water consumption is the proportion of water that is not returned to its source after it has been withdrawn. Water that is consumed is no longer available because it has evaporated, been transpired by plants, incorporated into products or crops, consumed by people or livestock, or otherwise been permanently removed from its source. Water discharge is the difference between water withdrawal and consumption. In other words, it is water that is not consumed and is returned to the original body of water. 
Energy and water are inextricably linked. Non-renewable energy resources currently dominate the global energy generation landscape. These thermal sources of energy generation, mostly derived from fossil fuels, are at present particularly waterintensive, mainly due to the cooling systems that they use. These cooling systems require large amounts of water. A push toward a less carbon-intensive energy sector with a larger share of renewables, stimulated by efforts to mitigate global climate change, requires careful consideration of the potential impacts of such an energy transition on the other nexus sectors. For example, low-carbon biofuels and hydropower are also very water-intensive, sometimes as much as fossil fuels in terms of water use per unit of energy generated. Energy use itself for biomass production may in some cases outweigh the energy that the biomass generates (SEI 2011).

Energy and water are also interconnected to food and agriculture. Agriculture is the largest user of fresh water globally, accounting for approximately $70 \%$ of freshwater withdrawals from rivers, lakes, and aquifers. This ratio can rise to up to 90\% in some developing countries. An increasing population and shifting dietary trends mean that the demand for food and feed crop cultivation is rising. Food production and its associated supply chain account for approximately one third of the world's total energy consumption (UN 2014). In many regions, rising food production has not only led to agricultural land expansion-largely at the expense of forests-but also to an intensification of agricultural processes on existing land. This simultaneous expansion and intensification place more stress on agricultural input resources such as water, energy, and fertilizers.

The implications on natural resources have been investigated of the baseline food and agriculture projections up to 2050 by the Food and Agriculture Organization (FAO 2006; Bruinsma 2011). Even though the growth rate in agricultural production continues to slow down - as a result of a declining population growth rate and a higher percentage of the world's population reaching medium to high levels of food consumption-agricultural production will need to rise by approximately $70 \%$ by 2050 to serve a $40 \%$ increase in population and rising average food consumption levels. Approximately $90 \%$ of the growth in crop production would be a result of higher yields and increased agricultural intensity, with the remainder being provided via land expansion. Mainly thanks to gradual improvements in water use efficiency, water withdrawals for irrigation would grow more slowly, but still increase by almost $11 \%$ by 2050 . In terms of the availability of both land and water, both of these resources are more than sufficient globally, but are unevenly distributed throughout the world. Certain regions or countries face scarcity of either land or water for crop production (Bruinsma 2011). Scarcity of these resources could restrict the potential for the expansion of agriculture and intensification of agricultural processes (IEA 2013).

While we recognize that the food and agriculture sectors are an essential part of the nexus, we do not focus on these areas in this chapter. The main aim of this paper is to develop an understanding of how different conventional and innovative energy technologies can be distinguished in relation to their water needs. This is another important part of the nexus. We investigate several energy scenarios and the future water requirements of these scenarios, including some in which climate policy is 
adopted. We develop a tool to analyze future short-, medium-, and long-term impacts of energy on water and the implications of energy and climate policy on these two resources. Much of what happens in the field of energy is determined by global climate change control; therefore, we inspect low-carbon technologies in particular. For our purposes here, we start by making an inventory of water withdrawal and consumption factors for a set of different fossil fuel-based and renewable energy technologies, much in line with - and relying on data reported in - earlier publications on this topic (Macknick et al. 2012; Meldrum et al. 2013). In the Appendix, we report the results of our findings, summarized in Figs. 7 and 8 (see also Halstead et al. 2014). These figures show how very different the water intensities of distinct energy technologies can be and that all of them are characterized by substantial uncertainty ranges.

\section{Case Study on the Middle East}

Since a few years, efforts are being undertaken to represent water availability and/or usage in IAMs (see, e.g., Bouckaert et al. 2014; McCarl et al. 2017). Nexus case studies have been performed with IAMs for specific countries, notably several in Africa and the MENA region (Al-Riffai et al. 2017; van der Zwaan et al. 2018). Our purpose here is to inspect with an IAM what the water withdrawal and consumption implications might be of two main types of scenarios for future energy needs and the technologies employed herein to meet these needs: a baseline and a stringent climate policy scenario. We do this for the Middle East, since it is one of the regions in the world where water stress is already today becoming evident (see, e.g., Doukas et al. 2017). Having reported in the Appendix the water intensities of a representative set of different energy technologies, we investigate scenarios that enable us to analyze which of the electricity generation options could potentially be most suitable for this particular region from a water use perspective. We also inspect the uncertainties associated with these scenarios, as well as the risks involved in them. Knowledge of water usage levels of the power sector in the Middle East allows public authorities to match them with data for water availability in this region, which can assist in designing appropriate energy and climate policy.

Our baseline scenario does not include existing and planned climate policies, which means that it does not include greenhouse gas (GHG) emission reduction targets stated by countries in their so-called Copenhagen and Cancun pledges. The baseline scenario does include policy measures on renewable energy that were in place before 2010: these are assumed to remain in effect in the foreseeable future. In the $2{ }^{\circ} \mathrm{C}$ climate policy scenario, we assume that enough low-cost options are deployed to reduce GHG emissions so as to reach the global $2{ }^{\circ} \mathrm{C}$ target, regardless of where in the world or in what sector the emission reductions take place. This corresponds to a globally harmonized action to mitigate climate change. An example would be a global carbon certificate market that involves GHG emission reduction obligations allocated purely on cost-efficiency criteria. This corresponds to a 
scenario in which the equilibrium concentration of GHGs in the atmosphere is at most 450 ppm (see, e.g., Kriegler et al. 2013).

The left-hand plot of Fig. 1 shows a possible baseline scenario for electricity generation in the Middle East, which is here defined as the collection of countries in the Levant and the Arabian Peninsula, including also Iran, Iraq, and Turkey. It represents just one of the many ways in which business-as-usual power production could expand over the next several decades, as substantial uncertainty prevails in this respect. This baseline constitutes quite a realistic scenario, given the large role it proffers for the use of natural gas in the power sector. Indeed, this resource is domestically abundant in the region. Our baseline has been developed with the bottom-up energy systems model TIAM-ECN, a tool to make internally consistent long-term energy supply and demand scenarios. For more details and examples of how this model can be used for energy and climate policy analysis, we refer to previous publications (see, e.g., van der Zwaan et al. 2013a, b; Kober et al. 2014; Rösler et al. 2014). As one can see, relatively modest roles are also reserved for coal and oil in power production in the baseline scenario, but by the middle of the century, natural gas remains practically the only fossil fuel left for electricity generation. Hydropower plays a non-negligible role throughout the forthcoming decades, given the potential of this option in countries like Iran and Turkey.

The right-hand plot of Fig. 1 shows how power supply may significantly alter over the next decades if one assumes that in the Middle East, just as elsewhere in the world, stringent climate policy is introduced capable of reaching the global $2{ }^{\circ} \mathrm{C}$ target. This scenario is calculated, and this target is met by applying a constraint on emissions of $\mathrm{CO}_{2}$ and other GHGs in the TIAM-ECN model. TIAM-ECN determines that the cost-optimal transition path involves not only a drastic reduction in the

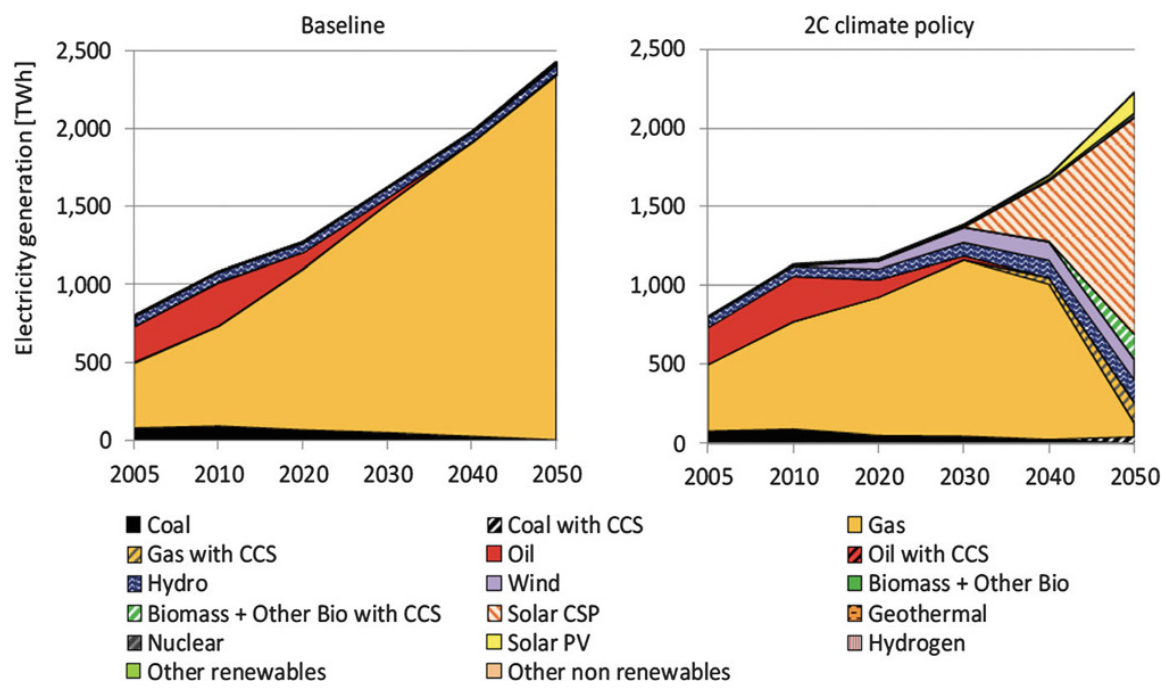

Fig. 1 Baseline and stringent climate policy scenario for power production in the Middle East 
role of the single most important fossil fuel, natural gas-while part of its use is subjected to CCS implementation-but also a massive introduction and diffusion of solar energy, in particular CSP. The latter makes sense in view of the large solar irradiation resources of the Middle East. In addition to CSP and some PV, relatively small but non-negligible roles are reserved for power production options such as biomass, wind, and hydropower. It also proves cost-effective to introduce a certain level of energy savings in this climate policy scenario, as evidenced by its lower overall level of power production in 2050 in comparison to that in the baseline. Otherwise, as could be expected, the climate change control stringency necessitates a massive introduction of low-carbon renewables. The precise nature of the renewable energy mix, however, is subject to a large amount of uncertainty, as many different combinations and levels of renewable energy types can achieve the $2{ }^{\circ} \mathrm{C}$ target.

\section{Results and Discussion}

Figure 2 depicts what the water withdrawal levels would be if we superimpose the water intensity factors reported in the Appendix onto the power production patterns of Fig. 1. The color shading of the left plot of Fig. 2 (for the baseline) looks similar to that of the left plot of Fig. 1, except for the fact that the oil and coal shares are slightly fatter in the former. This is an expression of the fact that the water withdrawal intensity of natural gas-based electricity generation is somewhat smaller than that of its fossil fuel counterparts. The color composition of the right plot of Fig. 2, on the other hand, looks very different from that of the right plot of Fig. 1. The reason is that, first of all, CCS - deployed in response to stringent climate policy-is a very

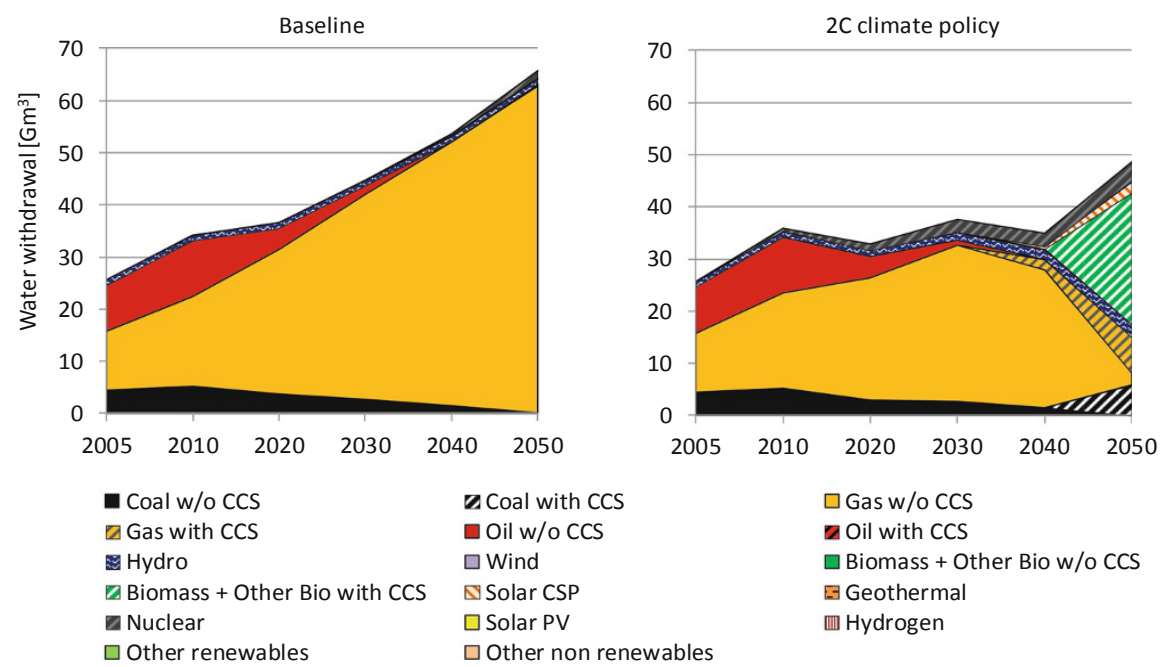

Fig. 2 Baseline and stringent climate policy scenario for water withdrawal in the Middle East 
water-intensive technology, as demonstrated by the large water withdrawal shares in Fig. 2 (right plot). This is especially apparent for the use of biomass in combination with CCS, since non-CCS biomass use for power production is also a very waterintensive option. In terms of water withdrawal, CSP possesses a much smaller water footprint, as evidenced by the relatively small contribution of CSP to the right-handside graph of Fig. 2. By its very nature, hydropower withdraws large amounts of water. Nuclear power, while hardly discernible in the right-hand-side graph of Fig. 1, occupies a disproportionally large share in the right-hand-side graph of Fig. 2, the explanation for which is the substantial water intensity of nuclear power as thermal electricity generation option.

Over the course of the coming few decades, it can be expected that at least four countries in the region (Iran, Saudi Arabia, United Arab Emirates, and Turkey) consume domestically produced nuclear-based electricity. The right plot of Fig. 3 shows that in terms of water consumption, the stringent climate policy scenario looks quite different from that in terms of water withdrawal. In the former case, CSP is by far the dominant force, since it is substantially more water-consuming than even biomass-based power production complemented with CCS technology. The exponential growth in water consumption in the climate policy scenario depicted in the right graph of Fig. 3 implies a risk in terms of whether sufficient water will be available to meet this demand. This risk needs to be carefully considered.

Underlying the results depicted in Figs. 2 and 3 are the cooling techniques associated with the respective individual electricity generation options, since these cooling technologies are responsible for the vast majority of the indicated water withdrawal and consumption levels. Figure 4 shows what the breakdown is today of different types of cooling techniques in the Middle East for each of the main current power generation alternatives. For calculating the water usage profiles shown in

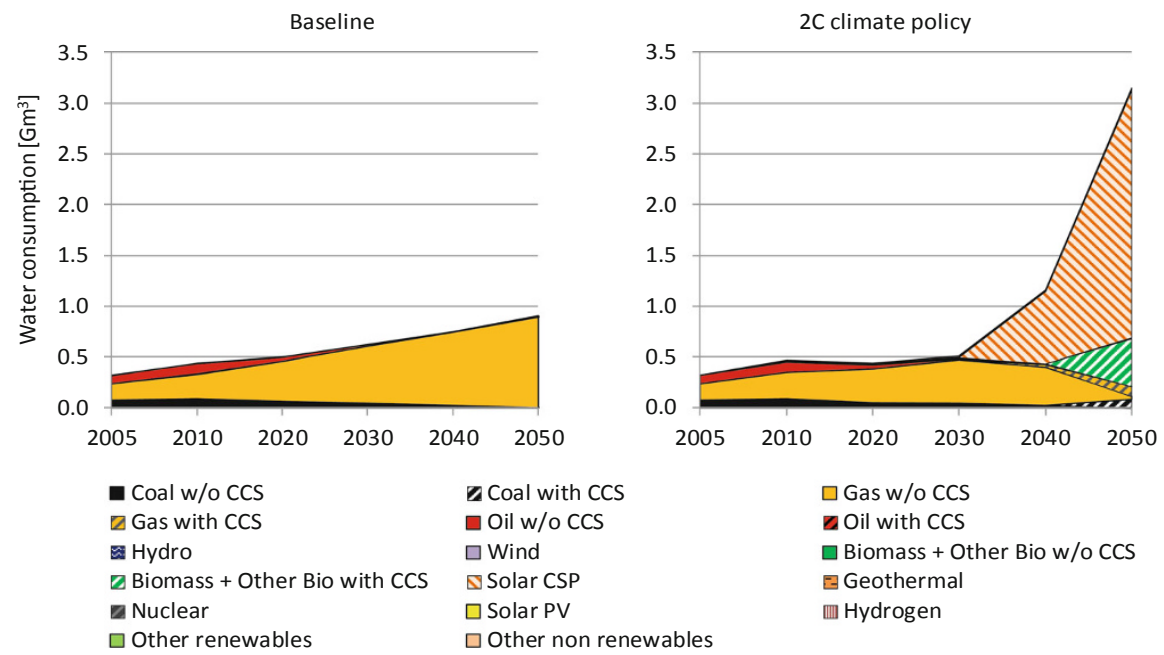

Fig. 3 Baseline and stringent climate policy scenario for water consumption in the Middle East 


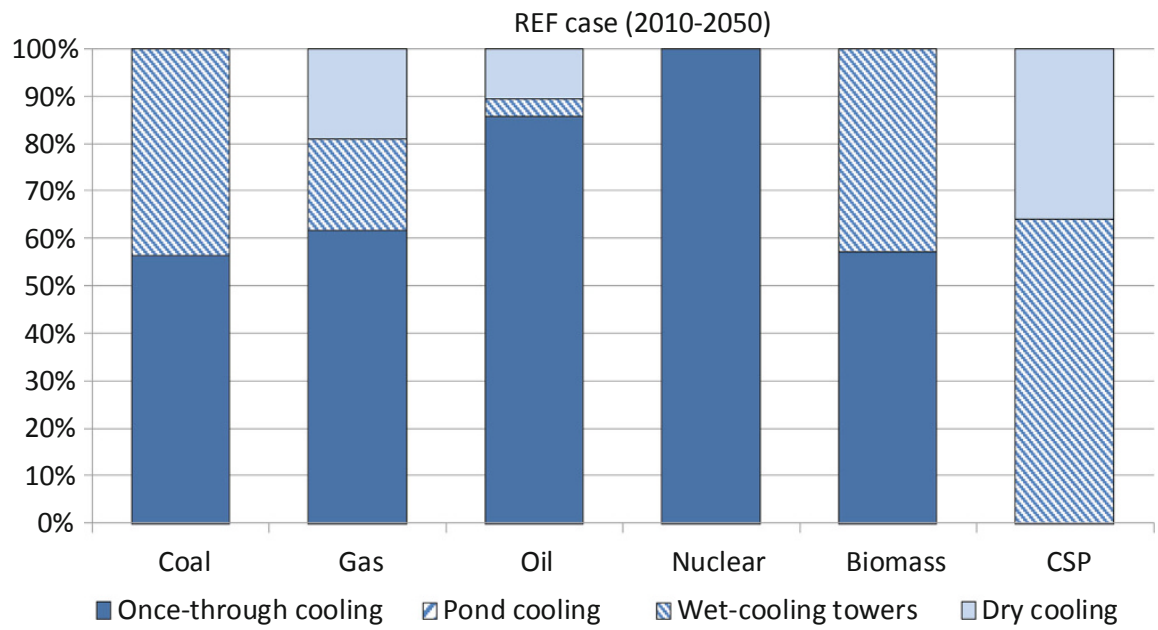

Fig. 4 Current and future shares of cooling techniques for the main power production options in the Middle East in the REF case

Figs. 2 and 3, we have assumed that this breakdown continues to hold until 2050, which we refer to as the reference (REF) case. In other words, for coal usage, for example, we assume that until the middle of the century about $55 \%$ of all power plants in this region remain equipped with once-through cooling technology (using either fresh or saline water), while $45 \%$ of the coal-based power plants use recirculating methods to cool (either with a cooling tower or pond-based techniques). Likewise, we assume that approximately $60 \%$ of natural gas-based power plants remain equipped with once-through cooling, while $20 \%$ of these plants use recirculating methods and another $20 \%$ dry cooling techniques. For CSP plants, we suppose that the current breakdown of some $65 \%$ of recirculating and $35 \%$ of dry cooling techniques continues to hold for the forthcoming decades.

Uncertainties abound with regard to the future relative shares of different cooling techniques, which is why we perform a sensitivity test for these shares. Due to serious water constraints in the Middle East, which may intensify over the years to come, it is likely that efforts will be made to reduce the water usage of power plants in the region. This can be achieved by replacing once-through cooling by recirculating cooling and/or substituting the latter with hybrid or dry cooling options. Such replacement will be a gradual process, given the capital intensity of both power plants and cooling technologies and since water constraints will probably gradually emerge in various locations rather than abruptly come to the fore in the region as a whole. A possible scenario for this process is depicted in Fig. 5, in which for all major electricity generation options (based on, respectively, coal, natural gas/oil, nuclear energy, biomass, and CSP) a pattern is supposed for the gradual phase-in of water-saving technologies. This scenario is referred to as the SAVE case. This case engenders additional costs, the overall magnitude of which needs to be considered in joint water-energy policy design. The SAVE case for the evolution of cooling 


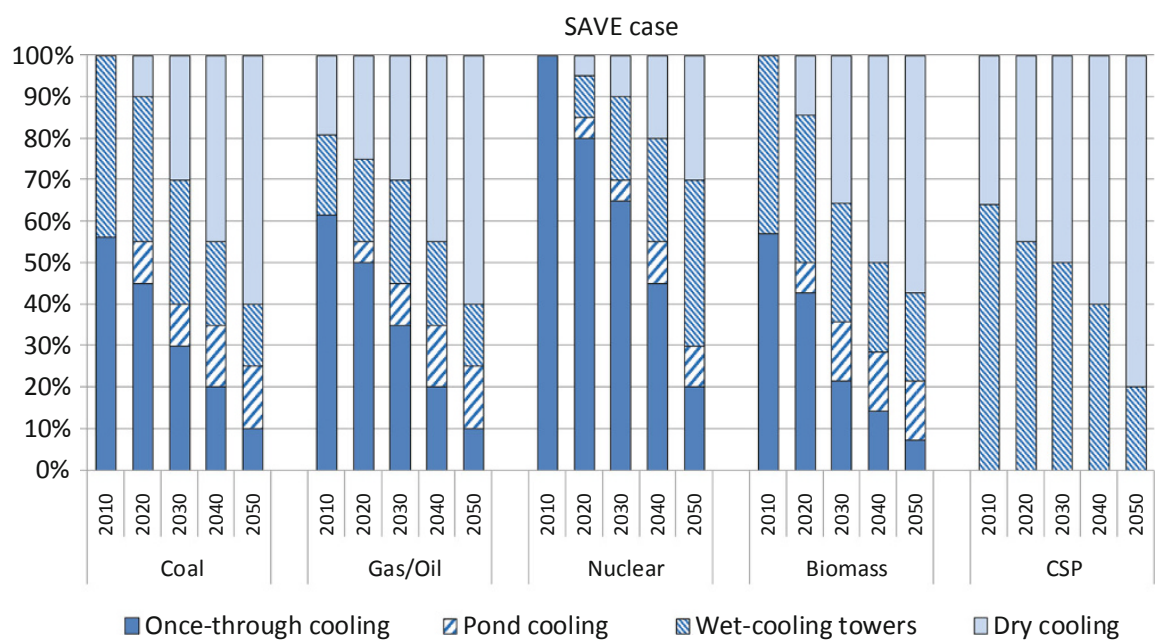

Fig. 5 Current and future shares of cooling techniques for the main power production options in the Middle East in the SAVE case

options has not been developed on the basis of a combined cost minimization procedure for energy and water technologies simultaneously, but on the basis of one for energy technologies only-this is one of the opportunities for improvement that we recommend to be explored in follow-up research. In practice, a SAVE case may thus materialize differently, that is, with other energy and water technologies.

Figure 6 shows how our water withdrawal and consumption projections modify, both in the baseline and stringent climate policy scenario, if one switches from REF-case cooling techniques to those we assume in the SAVE case. The large reduction in water withdrawal in the baseline scenario when switching from the REF to the SAVE case is obvious, which is mostly the result of the gradual phasing out of once-through cooling and the introduction of recirculating, hybrid, and dry cooling systems for natural gas-based power production (see the left-hand plot of Fig. 6). The same plot in Fig. 6 points out that this switch has little effect on water consumption levels during the first couple of decades, which can be explained by the fact that recirculating types of cooling actually possess slightly higher water consumption levels than once-through systems. In the period 2040-2050 though, a reduction in water consumption materializes of about $30 \%$, thanks to the savings introduced as a result of particularly dry cooling systems. These dry cooling systems do not use any water at all, by definition, as air is the principal medium used for cooling.

For the stringent climate policy scenario-see the right-hand plot of Fig. 6-we see a few notable differences. First of all, in terms of water withdrawal, the savings are substantially lower than in the baseline scenario, the explanation for which is the large role played in the climate change control scenario by CCS and biomass-based power production technologies. For water consumption, the difference between the 

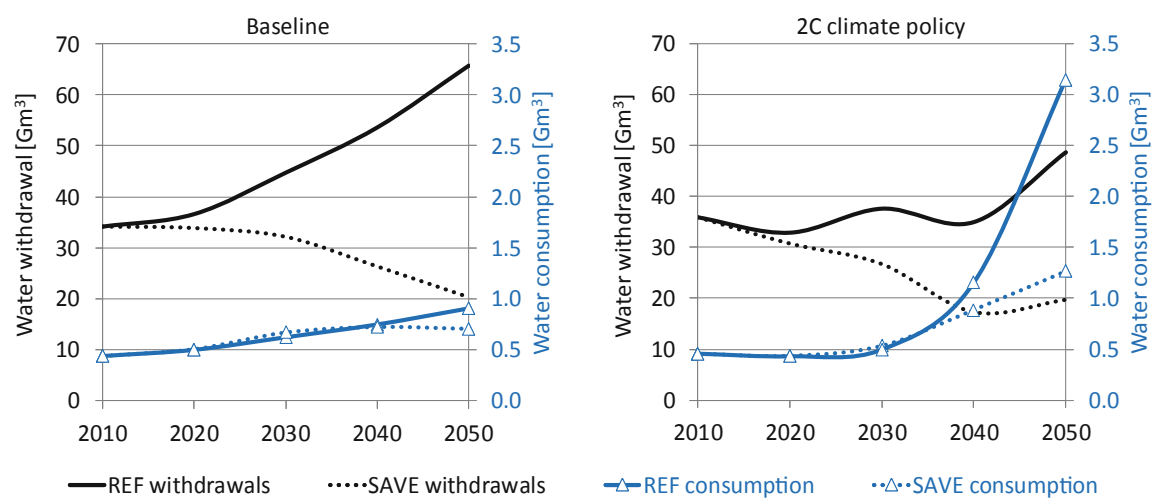

Fig. 6 Water withdrawal and consumption for two electricity sector scenarios under the REF and SAVE cases in the Middle East

REF and SAVE cases is small initially, like in the baseline scenario, but from about 2030, the discrepancy between these two cases becomes very large. The reason is that particularly CSP and, to a lesser extent, biomass are assumed to rely largely on dry cooling systems by the middle of the century in the SAVE case. Figure 6 demonstrates that there is substantial scope for water stress risk reduction, but that uncertainties abound as a result of unforeseeable developments in the application of cooling techniques.

An earlier study performed an investigation of scenarios for energy-water interdependencies in a similar as we have done here (Bouckaert et al. 2014). Its authors added water footprints related to the power system (including cooling systems, gasification, and flue gas desulfurization processes) to their global TIAM-FR energy system model. With their modification, the TIAM-FR model could be used to ascertain whether future energy mixes might be plausible in terms of water availability. The authors evaluated diverse policies concerning water and $\mathrm{CO}_{2}$ emissions and suggested that the choice for the cooling system and the use of CCS when applying climate policies to the energy system may significantly increase overall freshwater consumption. In our study, we confirm this finding, as can be seen from Fig. 6: if climate policy is implemented and no dedicated water consumption savings strategy is adopted, water consumption may exponentially increase, even in comparison to the baseline scenario. This is a risk that we should hedge ourselves against, certainly in a region like the Middle East.

In regions like the Middle East where water is already scarce today or is likely to become so in the relatively short run, an increase in freshwater consumption levels or withdrawals may not be sustainable for the energy system. Hence, we suggest that in the future, we adapt TIAM-ECN so as to incorporate water use factors, which would allow us to consider limited water availability as a constraint, and evaluate the impact of water scarcity on electricity production in a region such as the Middle East. Even better, in subsequent research, we could improve our model so as to introduce the costs of cooling systems as well as the costs of water employed therein. 
Indeed, water usually does not receive a cost price in IAMs - contrary to energy services - so that the impacts on and from water usage normally do not become visible. The inclusion in our type of models of the costs of water and those of cooling systems would allow us to perform a combined cost minimization analysis of energy and water systems simultaneously. It could well prove that the resulting optimal regional energy systems look different from the ones that we obtain with the current version of our model without water cost inclusion, based on cost minimization of the energy system only. Given that the subjects of energy and water are becoming increasingly intertwined in a future climate-constrained world, joint water-energy analysis would not only be an exciting type of new research but may also constitute an essential requirement for any study that attempts to determine the desirable energy system of the future.

\section{Conclusions and Recommendations}

This chapter has shown that both the energy and water sectors face key challenges over the coming decades. We have demonstrated that in many respects these challenges are interrelated and thus need to be simultaneously addressed. The joint challenges associated with the energy-water nexus, however, are clearly different from those for climate change. The former may pose substantial problems at the local or regional level, but that are often addressable, one way or the other. They may in some cases last only relatively short periods of time, although potential solutions may sometimes come at a high cost. The latter is a truly global problematique with challenges that are not easily solvable and are long-lived, that is, span centuries. The costs required to mitigate climate change, although quite uncertain, may amount to percentage points of global world product. In this chapter, we directed our attention primarily to the energy-water nexus, rather than the energy-climate nexus, while addressing-from a scenario analysis perspective- the possible effects of climate change mitigation policy on the former.

The first main conclusion that we draw from our work is that the type of cooling system used for electricity generation is at least as influential for the water needs of power production as the type of energy technology used. This is certainly the case for conventional thermal power generation technologies, such as those based on coal, natural gas, oil, and nuclear energy, but possibly also for other more modern techniques, including a renewable energy technology such as CSP. This does not apply, however, to renewable energy technologies like PV and wind, which do not require water for cooling purposes.

Second, as reported in the Appendix (see also Halstead et al. 2014), we conclude that even when taking the full life cycle into consideration, PV and wind technologies remain the least water-intensive electricity generation options relative to other energy technologies considered in this chapter. This is true even when we only take into account the operational phase for the other energy technologies (thereby making in some sense an unfair comparison), and irrespective of the fact that the water 
footprint of PV and wind electricity options in the stages of manufacturing and production is often relatively high in comparison to other energy technologies. Indeed, the very high water use of technologies such as based on coal, natural gas, and oil, or nuclear energy and CSP, results predominantly from the operational phase of electricity generation. Overall, technologies like PV and wind thus appear to be clear winners in terms of water savings potential.

Third, it has been suggested in the literature-and we support this claim—-that in certain world regions, water availability is becoming as important a concern as security of energy supply. In view of the linkages between water and energy supply, integrated optimization analyses and policies regarding energy and water resource systems are necessary. Rather than first finding least-cost energy systems and subsequently finding the least-cost water supply that these systems require, instead one should attempt to minimize the costs of energy-water systems jointly.

Fourth, due to water constraints, it is likely that further efforts will need to be made to reduce the water usage of power plants in regions such as the Middle East. To achieve these reductions, once-through cooling may need to be replaced by recirculating cooling, which in turn can be substituted by hybrid or dry cooling options. The gradual increase of regional water constraints may make these replacements necessary, but the capital intensity of both power plants and cooling technologies will mean that such replacements will need to take place over decades.

Fifth, in a future that involves more stringent climate policy, a large role may be reserved for CCS and biomass-based power production, which requires large quantities of water. The water withdrawal savings that otherwise could be achieved in a business-as-usual scenario would perhaps be overshadowed by the sizeable water usage of these low-carbon technologies. This is an example of the kind of trade-offs that policy-makers need to consider when designing and implementing climate policies as well as policies related to the energy-water nexus sectors.

Sixth, we conclude that while regions exist today where already substantial water stress risks exist, the problems in principle-from at least a technical perspectivecan often be overcome, albeit sometimes at a high cost. In the long run, both water withdrawal and consumption can be reduced significantly if decisions are madeparticularly (but not only) in the field of energy production and consumption-that take water issues into account. We thus find that water stress issues, also in those regions where at present they are not yet apparent but may emerge in the future, can often be addressed either by using different energy and water (cooling) technologies or by relocating certain (e.g., industrial) activities to different regions. The real question though is at what cost.

Acknowledgments We would like to acknowledge the feedback from two anonymous referees and the editors of this volume, as well as the comments from colleagues who reviewed earlier versions of our work, as a result of whose expert advice this chapter improved substantially. We thank the TRANSRISK project (EU Horizon 2020 research and innovation program, grant agreement No. 642260) for its financial support. 


\section{Appendix}

Figures 7 and 8 provide a visual representation of the ranges of water withdrawal and consumption for different energy technologies based on our review of the relevant literature. For more details behind our analysis, literature review, and acquired data, we refer to our report "Understanding the Energy-Water Nexus" (Halstead et al. 2014), available at www.ecn.nl.

We do not include geothermal and hydropower generation sources due to the diversity of technologies used within these two categories that all involve widely diverging water usage factors-deviating from each other sometimes by several orders of magnitude. Technologies within these two categories are also inherently complex, and it is difficult to assess their water withdrawal and consumption factors with a credible degree of accuracy, unless entire studies are dedicated to each of them. We also omit tidal energy, for similar reasons. The impact of electricity generation from tidal power on water resources may be considered minimal as it could be argued that there is no withdrawal or consumption of water during the operational phase. However, we would recommend future studies on the water withdrawal and consumption factors for all these technologies.

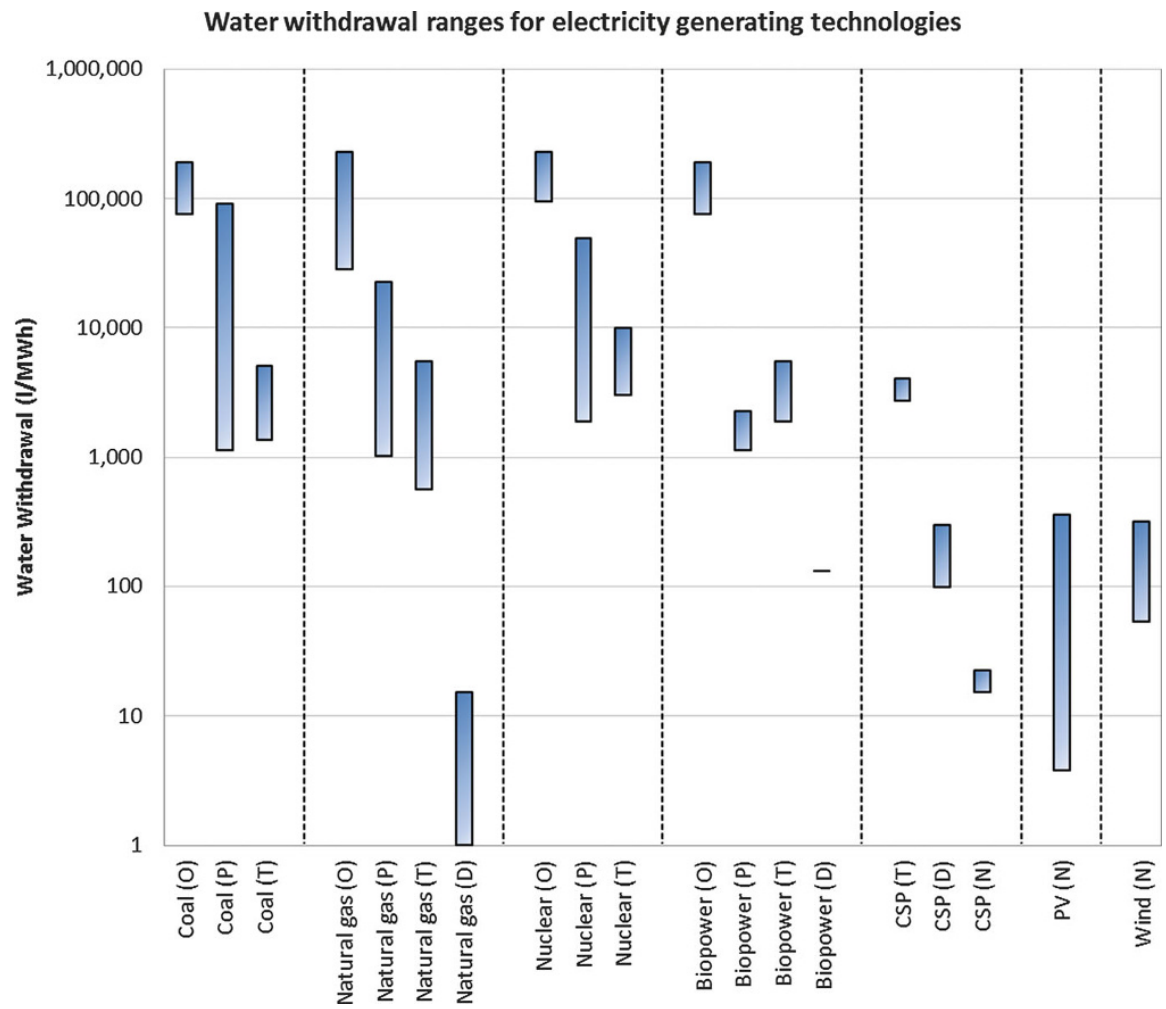

Fig. 7 Water withdrawal factors for electricity generating technologies 


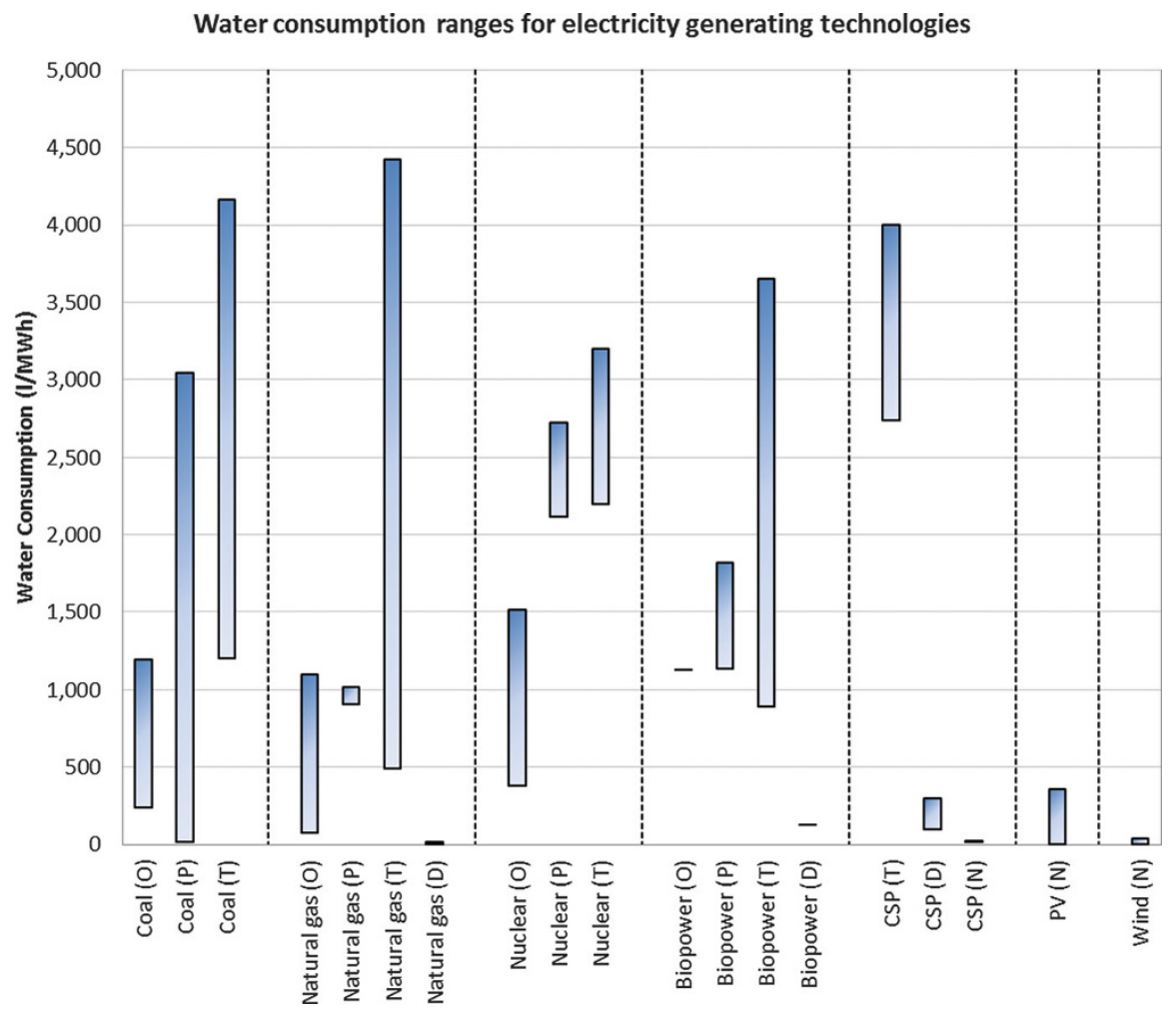

Fig. 8 Water consumption factors for electricity generating technologies. Notes: The different types of cooling system are given in brackets following the energy technology ( $\mathrm{O}$ once-through, $\mathrm{P}$ pond, $\mathrm{T}$ tower (both pond and tower are recirculating systems), $\mathrm{D}$ dry, $\mathrm{N}$ no cooling). The withdrawal and consumption factors for both PV and wind are life cycle estimates which include water withdrawal for power plant procurement and building and fuel extraction, transportation, and recycling. Life cycle data is taken from Meldrum et al. (2013). The data for PV does not include water use of concentrated PV. Withdrawal factors can be approximately 16 times higher for concentrated PV technology. The higher water use of concentrated PV is likely to be because of certain shared operational characteristics with CSP, such as a need for mirror washing (Meldrum et al. 2013)

Our analysis broadly agrees with the previous literature studies by Macknick et al. (2012) and Meldrum et al. (2013) showing that large differences in both water withdrawal and consumption levels exist between not only different types of electricity generating technologies but especially between the cooling systems used. The results show that the cooling system that is adopted often impacts water usage more than the actual electricity generating technology being used. As an example, oncethrough cooling systems can withdraw between 10 and 100 times more water per unit of electricity generation than cooling tower technologies, but cooling towers can consume typically twice the amount of water of once-through systems (Macknick et al. 2012). 
Once-through cooling systems withdraw the highest amount of water per MWh of electricity produced within each of the applicable generation sources (coal, natural gas, nuclear, or biopower). Generally, closed-loop pond cooling systems are the next biggest withdrawers of water, followed by towers, and finally dry cooling which uses minimal water for cooling purposes. This general declining trend of water withdrawal from once-through to dry cooling systems for each of the energy generation technologies can be seen in Fig. 7.

With respect to the water consumption of different technologies, the trend that is seen in water withdrawal is somewhat reversed. Once-through cooling systems return almost all of the water withdrawn back to a water body (only a small amount of water is lost via evaporation); hence, water consumption factors are relatively low compared to water withdrawal for each of the generation technologies. Recirculating cooling systems (ponds and towers) retain water that is withdrawn from water bodies for reuse; therefore, the water consumption of these systems is higher than for oncethrough systems. This increasing trend for each technology is shown in Fig. 8.

Although the water footprints of fossil fuel-based generation technologies such as coal and natural gas are high, our analysis shows that the withdrawal and consumption factors for both bioenergy and CSP are also large. The water use of these renewable technologies may influence policy-making as countries move toward low-carbon development and begin to deploy renewables on a mass scale, especially in regions of the world where water scarcity is an important factor. Large-scale deployment of renewable energy technologies will be reliant upon, yet at the same time have serious consequences for, water availability.

The data in the two figures above relate predominantly to water withdrawal and consumption during the operational phase of electricity generation. However, from our research, we have identified that the water footprints of both PV and wind in other life cycle phases are relatively significant compared to their footprints during the operational phase. Therefore, we have used water withdrawal and consumption factors for PV and wind that include water usage during the stages of power plant procurement and building, as well as fuel extraction, transportation, and recycling. This is the case in both Figs. 7 and 8. The water footprints of the remaining technologies, during these other life cycle phases, are not included as part of this analysis as they have minimal impact on the data. It can be seen that even when taking the full life cycle into consideration for PV and wind technologies, they remain the least water-intensive electricity generation options. This conclusion is supported by previous work by Meldrum et al. (2013), which incorporates a life cycle analysis of water consumption and withdrawal of different electricity generating technologies. It is important to emphasize here though that despite renewable energy sources generally using less water than fossil fuels, if a full life cycle analysis is performed for bioenergy, then this technology would become by far the most water-intensive option.

Using dry cooling can reduce freshwater usage. However, this may lead to increased costs and decreased plant efficiency. CSP using dry cooling might lead to an annual reduction in electricity output of 2-5\% and an increase in levelized cost of electricity of 3-8\% compared to wet cooling systems. In the United States, the 
annual performance loss of switching to dry cooling from wet cooling systems is $6.8 \%$ for nuclear facilities, $1.7 \%$ for combined cycle plants, and $6.9 \%$ for other fossil fuel-based generation plants.

The cooling system chosen is likely to play an important role in our future electricity generation mix. Given future uncertainties surrounding water availabilities and the consequences for power plants, particularly in regions of water scarcity, the use of alternative cooling techniques, such as dry cooling, may be necessary. Utilizing dry cooling or non-freshwater resources avoids some of the risks associated with drought and climate change. By 2035, water withdrawal could potentially increase by $20 \%$ and water consumption by $85 \%$, if we shift toward higherefficiency power plants with more advanced cooling systems that reduce water withdrawal levels, but increase water consumption.

\section{References}

Al-Riffai, P., Breisinger, C., Mondal, A. H., Ringler, C., Wiebelt, M., \& Zhu, T., (2017). Linking the economics of water, energy, and food: A nexus modeling approach (IFPRI, Egypt Strategy Support Program, working paper 4). Washington, DC.

Bouckaert, S., et al. (2014). A prospective analysis of waste heat management at power plants and water conservation issues using a global TIMES model. Energy, 68, 80-91.

Bruinsma, J. (2011). The resources outlook: By how much do land, water and crop yields need to increase by 2050? In P. Conforti (Ed.), Looking ahead in world food and agriculture: Perspectives to 2050 (pp. 1-33). Rome: Food and Agriculture Organisation of the United Nations.

Doukas, H., Karakosta, C., Taoumi, M., Wouters, F., \& Makarouni, I. (2017). Analysis of key areas for EU and GCC cooperation in the field of clean energy and the linked sectors of climate and water. Geopolitics of Energy, 39(10), 1-16.

FAO. (2006). Food and Agriculture Organization. United Nations, Rome. www.fao.org

Halstead, M., Kober, T., \& van der Zwaan, B. (2014). Understanding the energy-water nexus. Energy Research Centre of the Netherlands (ECN), ECN-E-14-046, Amsterdam.

IEA. (2013). Redrawing the energy-climate map: World energy outlook special.

Kober, T., et al. (2014). Emission certificate trade and costs under regional burden-sharing regimes for a $2^{\circ} \mathrm{C}$ climate change control target. Climate Change Economics, 5, 1-32.

Kriegler, E., et al. (2013). "What does the $2^{\circ} \mathrm{C}$ target imply for a global climate agreement in 2020?" The LIMITS study on Durban Platform scenarios. Climate Change Economics, 04, 04.

Macknick, J., Newmark, R., Heath, G., \& Hallett, K. C. (2012). Operational water consumption and withdrawal factors for electricity generating technologies: A review of existing literature. Environmental Research Letters, 7, 045802.

McCarl, B. A., Yang, Y., Schwabe, K., Engel, B. A., Mondal, A. H., Ringler, C., \& Pistikopoulos, E. N. (2017). Model use in WEF nexus analysis: A review of issues. Current Sustainable Renewable Energy Reports, 4, 144-152.

Meldrum, J., Nettles-Anderson, S., Heath, G., \& Macknick, J. (2013). Life cycle water use for electricity generation: A review and harmonization of literature estimates. Bristol: IOP Publishing.

OECD. (2017). The land-water-energy nexus: Biophysical and economic consequences. Paris: OCED.

Rösler, et al. (2014). Electricity versus hydrogen for passenger cars under stringent climate change control. Sustainable Energy Technologies and Assessments, 5, 106-118. 
SEI. (2011). Understanding the nexus. In Background paper for the Bonn 2011 Nexus ConferenceThe Water, Energy and Food Security Nexus: Solutions for the Green Economy.

UN. (2014). The United Nations World Water Development Report 2014: Water and Energy. Paris: UNESCO.

van der Zwaan, B. C. C., Cameron, L., \& Kober, T. (2013a). Potential for renewable energy jobs in the Middle East. Energy Policy, 60, 296-304.

van der Zwaan, B., et al. (2013b). A cross-model comparison of global long-term technology diffusion under a $2^{\circ} \mathrm{C}$ climate change control target. Climate Change Economics, 4(4), 1-24.

van der Zwaan, B., Boccalon, A., \& Dalla Longa, F. (2018). Prospects for hydropower in Ethiopia: An energy-water nexus analysis. Energy Strategy Reviews, 19, 19-30.

Open Access This chapter is licensed under the terms of the Creative Commons Attribution 4.0 International License (http://creativecommons.org/licenses/by/4.0/), which permits use, sharing, adaptation, distribution and reproduction in any medium or format, as long as you give appropriate credit to the original author(s) and the source, provide a link to the Creative Commons license and indicate if changes were made.

The images or other third party material in this chapter are included in the chapter's Creative Commons license, unless indicated otherwise in a credit line to the material. If material is not included in the chapter's Creative Commons license and your intended use is not permitted by statutory regulation or exceeds the permitted use, you will need to obtain permission directly from the copyright holder. 